\title{
EXPERIMENTAL STUDY ON SEISMIC PERFORMANCE OF PEC COMPOSITE COLUMN-STEEL BEAM FRAME WITH WELDED T-STUB STRENGTHENED CONNECTIONS
}

\author{
Jin Feng ${ }^{1,}{ }^{*}$, Jing Jin ${ }^{1}$, Jun Xia ${ }^{2}$ and You-Zhen Fang ${ }^{1}$ \\ ${ }^{1}$ Jiangsu Key Laboratory of Structure Engineering, Suzhou University of Science and Technology, Suzhou 215011, China \\ ${ }^{2}$ Xi'an Jiaotong-Liverpool University, Suzhou 215123, China \\ *(Corresponding author: E-mail: fengjin@mail.usts.edu.cn)
}

\section{A B S T RA C T}

Seismic performance of innovative Partially Encased Composite (PEC) column-steel beam composite frame was investigated, where the connection was strengthened by the welded T-stub. A $1 / 2$ scale, two-storey, and one bay composite frame specimen was designed and fabricated for the quasi-static test. Through the experimental observation and measurements, the seismic performance were evaluated, including hysteretic characteristic, lateral stiffness, seismic energy dissipation, and ductility. The plastic damage evolution process and ductile failure mode were clarified. The results indicated that the welded T-stud strengthened connection enhanced the integrity of the frame and led to higher seismic strength and larger lateral stiffness. The plastic hinge was observed away from the beam end due to the welded T-stud and the specimen exhibited an approximately completed hysteretic loop. Without significant decreasing of the ultimate bearing capacity, its overall drift, ductility efficient and equivalent viscous damping ratio were $3.63 \%$ (push) / 4.07\% (pull), 3.21 (push) / 3.70 (pull) and 0.261 respectively. The proposed structure possesses sound deformation, ductility, and energy-dissipation capacity with the desired plastic failure mode induced by the plastic hinges formed in all beam sections near the T-stud end and column section at the bottom, successively. It was demonstrated an ideal ductile energy-dissipation mode of the frame structure.

\section{A R T I C L E H I S T O R Y}

$\begin{array}{ll}\text { Received: } & \text { 24 June } 2020 \\ \text { Revised: } & \text { 16 March 2021 } \\ \text { Accepted: } & \text { 18 March 2021 }\end{array}$

\section{K E Y W O R D S}

Welded T-stud strengthened connection;

PEC column with crimping steel panel composite section; Composite frame structure; Seismic performance; Quasi-static test

\section{Introduction}

Partially Encased Composite Column (PEC column [1]) is a new type of composite member proposed to enhance the lateral stiffness and bearing capacity of conventional I-shaped or $\mathrm{H}$-shaped steel columns in steel structures. Tremblay R [2], Prickett BS [3], Zhao Gentian [4], and Fang Youzhen [5, 6] conducted monotonic axial compression tests under unbiased or biased loading, and quasi-static experiments on PEC columns. The results showed that the PEC column fully utilized concrete and the concrete-filled steel tube structure to achieve higher axial bearing capacity, greater lateral stiffness, and superior seismic resistance. This new type of structural component with a straightforward connection design is also convenient to construct. Laterally, the PEC column reduced noticeable stiffness inequality in principal axes and improved seismic ductility. An innovative crimping PEC column with curving steel panels was suggested. Test results showed it can be applied in various cases with different steel dimensions. Its construction is further simplified because the use of steel panel links between the flanges of the curing end. The steel plate further mitigates the defects of unbalanced bidirectional stiffness.

The $\mathrm{T}$-stud connection is a rigid connection proposed in the current design code of China [7], and it exhibits a large bending rigidity and strength. The plastic hinge usually forms at the location away from the beam end region to meet the seismic requirements of "strong joints". Therefore, the T-stud connection has been listed as one of the common connection types for concrete-filled rectangular tubular columns [8]. He et al. [9] carried out an experimental investigation on beam-column joints connected by T-stubs. The calculation equations for shear resistance were also proposed. Hao et al. [10] investigated the seismic performance of steel frame with beams connected by T-stubs. It was concluded that the bolt-on connection was the most reasonable connection type to ensure the force transfer at the beam-column joint of composite structure. Peng [11], Wang [12], and Fang [13, 14] tested a series of beam-column joints under seismic loading with a bolt-on connection. Their study showed that the tensile force in the beam was converted into the compressive force of the concrete in the joint, due to the presence of the bolt-on connection. The concrete in the joint transfer forced through an inclined compressive strip, which had a high shear resistance. The bolt-on connections also presented a partial self-alignment effect, which also reduced the residual deformation of the joint connection.

Fang $[15,16]$ studied the seismic behavior of the interlayer substructure specimens welded with T-stubs extracted from a PEC column-steel beam composite frame. Their results showed that the T-stub connection joint exhibited a large bending stiffness. The design target of forming the plastic hinge away from the joint was achieved since the plastic yielded at the beam end.
It was also found that the integrity of the interlayer substructure was well maintained. The horizontal lateral stiffness was evenly distributed along with the height, and the specimen exhibited an ideal reversed triangular shear deformation mode. Furthermore, the interlayer substructure displayed the ductile failure mode through the plastic hinge formed near the end of the T-stubs Through the experiments and numerical simulation, the performance of T-stud with different flange thicknesses were also investigated. For the connection under monotonic loading mode, it was concluded that the existing design standards underestimated the resistance of the T-stub connection [17]. Sebbagh [18] performed the monotonic and cyclic loading tests on the t-stub connection with two and four bolts per row. It was found out that the outer row of the bolts prevented the reduction of stiffness and the uplifting of the end part of the t-stub plate, therefore, are highly recommended.

New types of connections for steel and composite steel frame have been proposed by researchers, such as improved direct-welded connections [19], and double-ribbed reinforced connections [20], as well as new testing methods, such as bi-axial lateral loading [20]. This study revisited the T-stub connections and conducted the quasi-static test on a $1 / 2$ scale, two-storey single-span PEC column-steel beam composite frame with T-stud welded reinforced jointed and rolled steel plates. Along with previous investigations on PEC column components, joints, and interlayer substructures, the seismic performance of large-scale PEC column structures was studied, including hysteretic behavior, lateral stiffness, energy dissipation, ductility, and failure modes.

\section{Experiment program}

\subsection{Specimen design}

The detailed design of the PEC column specimen is illustrted in Fig 1. The span of the test piece was $2000 \mathrm{~mm}$, and the column of first and second floor are both $1500 \mathrm{~mm}$ in height. The top of the PEC column was connected to the rigid loading beam by planar hinges to achieve an even load, while the bottom of column was rigidly anchored to the floor beam. The steel member in the PEC column was made by welded Q235 steel plates. The flange was $310 \times 5$ steel plate with $30 \mathrm{~mm}$ sides curl and the web was $240 \times 5$ steel plate. The dimension of the drawbar plate was $220 \times 30 \times 4$. I20a section was used for the steel beams. T-stud was used to connect the PEC column and steel beam by a combined approach of welding and high-strength bolt connection. The nominal diameter of the bolt was $20 \mathrm{~mm}$, and the material strength grade was 10.9 with a designed preload at $10 \mathrm{kN}$. The T-stud was welded by three sides fillet weld to connect to the steel beam. Representative specimens were cut from the steel frame of the PEC column, the steel beam flange, and the corresponding part of the web for 
the determination of tensile properties. The material properties of steel are summarized in Table 1. The compressive strength of concrete used in the PEC column was determined by three $150 \mathrm{~mm}$ cubes following Chinese Code standard. The average compressive strength of the concrete used for the column is $\mathrm{f}_{\mathrm{m}}=19.6 \mathrm{MPa}$.

\subsection{Experimental setup}

The experimental setup is shown in Fig 2a). Displacement gauges DT1 to DT5 were used to obtain the horizontal displacement of the frame. The rotation angle of the connection between the PEC column and steel beam was measured by displacement gauges DT6 to DT9, and the rotation at the beam end can be obtained from displacement gauges DT10 to DT13. The stress state of the PEC column and beam at the end critical sections and joint can be derived from the strain measurements.

\subsection{Loading protocol}

The Displacement of the loading beam was limited by the pressure beam and the hydraulic actuator. The out-of-plane deformation of the loading beam is limited by the supports, as shown in Fig. 2b).

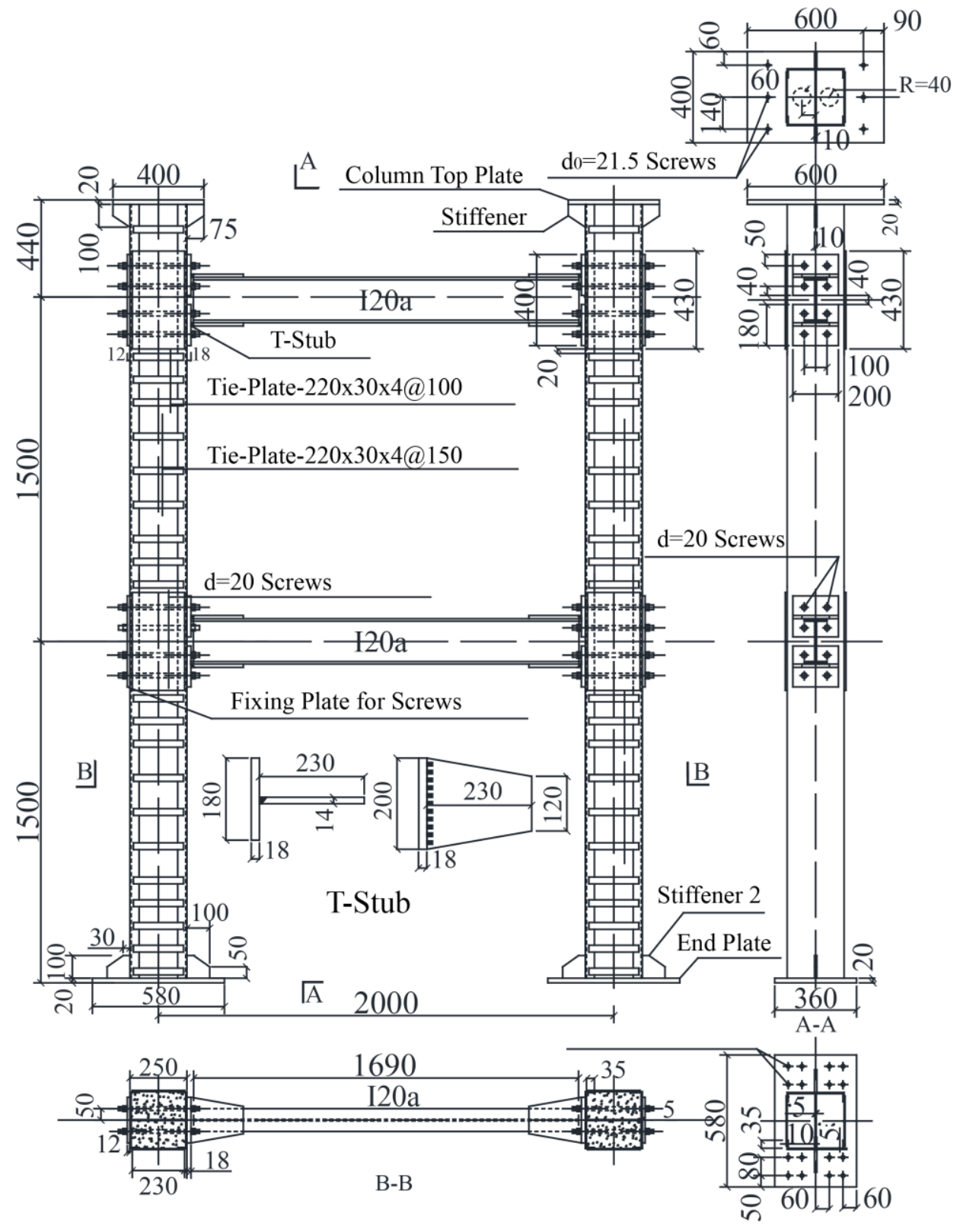

Fig. 1 Construction details of the Test specimen

Table 1

Mechanical properties of steel specimens

\begin{tabular}{|c|c|c|c|c|}
\hline Location & $\begin{array}{c}\text { Yield Strength } \\
f_{\mathrm{y}} \\
\mathrm{MPa} \\
\end{array}$ & $\begin{array}{c}\text { Tensile Strength } \\
f_{\mathrm{u}} \\
\mathrm{MPa} \\
\end{array}$ & $\begin{array}{c}\text { Modulus of elasticity } \\
E \\
\mathrm{MPa} \\
\end{array}$ & $\begin{array}{c}\text { Elongation } \\
\delta \\
\% \\
\end{array}$ \\
\hline Column Web and Flange & 294 & 414 & 2.00 & 22.8 \\
\hline Beam Flange & 294 & 447 & 2.00 & 22.8 \\
\hline Beam Web & 293 & 440 & 1.98 & 19.9 \\
\hline
\end{tabular}




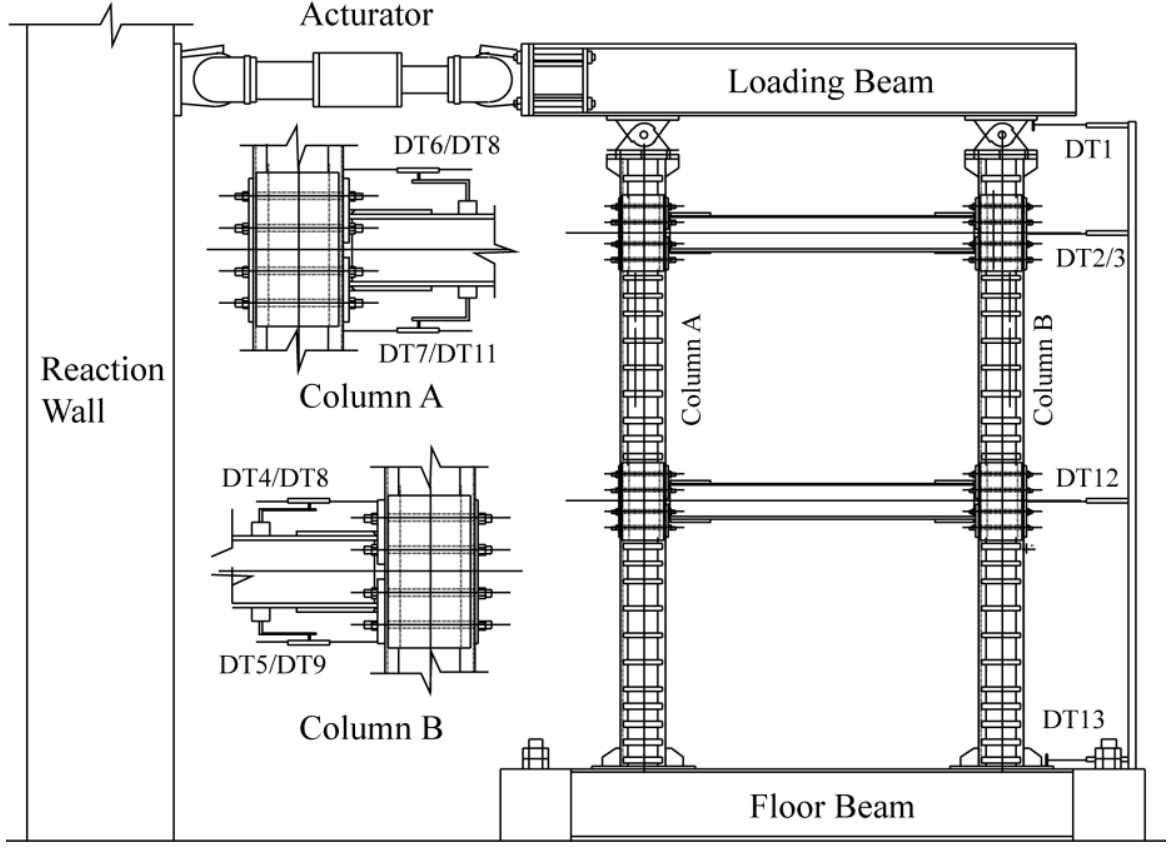

(a) Measurement and Instrumentation

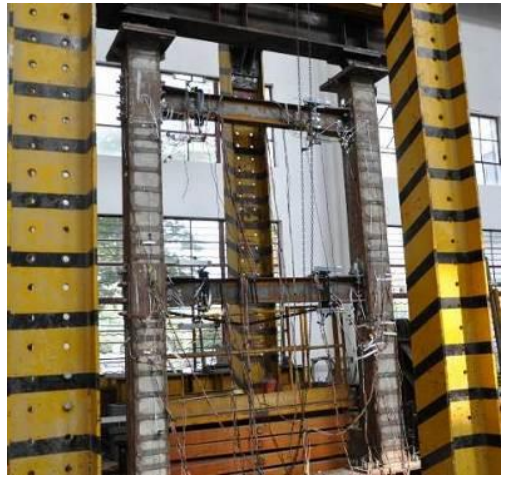

(b) Test setup and specimen configuration

Fig. 2 Loading scheme of test

Similar to previous studies [21], the displacement control loading mode is adopted. However, the actual seismic characteristics were considered, which means frequent earthquakes with higher probability were enforced for a higher number of cycles and rare earthquakes with less probability were enforced with lower number of cycles as shown in Table 2. Before the seismic loading test, the frame was preloaded to ensure the proper working condition of all measuring instruments. The loading test was terminated when the bearing capacity of the frame had dropped to $85 \%$ of its ultimate bearing capacity or the lateral displacement exceeded the lateral drift limit, which was 1/30 of the floor height under a rare earthquake scenario. The full loading protocol is shown in Table 2 .

\section{Experimental observations and failure mode}

The column specimen remained elastic state during the initial stage of loading, so there was no obvious deformation. When the specimen was loaded to the displacement of $34 \mathrm{~mm}(\delta=0.958 \%)$, obvious peeling off was observed at the inner surface of the cross-section flange near the T-stub (as shown in Fig 3 (a)). When reaching the displacement of $51 \mathrm{~mm}(\delta=1.437 \%)$, the yielding line of the web near the T-stub initiated at the beam ends and then gradually extended to the inner side of the cross-section. The T-stub of the beam was eventually pulled out from the PEC column and thus debonded, as shown in Fig 3 (b). Further loading to a displacement of $68 \mathrm{~mm}(\delta=1.915 \%)$, the cross-section yield line at the beam end near the T-stub penetrated the entire section and finally formed a plastic hinge (as shown in Fig 3(c)). When displacement reached $102 \mathrm{~mm}(\delta=2.873 \%)$, the plastic hinge area near the T-stub of all beam ends was continuously extended along the span (see Fig. 3(d)), and the concrete of the PEC column was crushed due to great deformation of the external flange of the frame components (see Fig. 3(e)). The concrete at the bottom of PEC column was also crushed at a displacement of $136 \mathrm{~mm}(\delta=3.831 \%)$, due to the intensive deformation of the steel flange. The plastic hinge was formed at the bottom of PEC column, which presented a plastic failure mechanism. The plastic hinge area developed severely into the span after reaching the displacement of $153 \mathrm{~mm}(\delta=4.310 \%)$. The outer flange of the bottom of column A is torn near the joint with the welded bottom plate (see Fig 3(f)). The lateral displacement of the specimen exceeded the requirement of $1 / 30$ of the floor height under the rare earthquake level, and the loading test was thus terminated

Table 2

Loading protocol

\begin{tabular}{cccc}
\hline $\begin{array}{c}\text { Loading } \\
\text { Stages }\end{array}$ & $\begin{array}{c}\text { Displacement } \\
\Delta / \mathrm{mm}\end{array}$ & $\begin{array}{c}\text { Shifting } \\
\delta / \%\end{array}$ & $\begin{array}{c}\text { Number of } \\
\text { cycles }\end{array}$ \\
\hline 1 & 13 & 0.366 & 6 \\
2 & 17 & 0.479 & 6 \\
3 & 26 & 0.732 & 6 \\
4 & 34 & 0.958 & 4 \\
5 & 51 & 1.437 & 2 \\
6 & 68 & 1.915 & 2 \\
7 & 85 & 2.394 & 2 \\
8 & 102 & 2.873 & 2 \\
9 & 119 & 3.352 & 2 \\
10 & 136 & 3.831 & 2 \\
11 & 153 & 4.310 & 2 \\
\hline
\end{tabular}

Note: shifting $\delta=\Delta / H$, where $\Delta$ is the displacement of the actuator, $H$ is the distance between the specimen and the actuator.

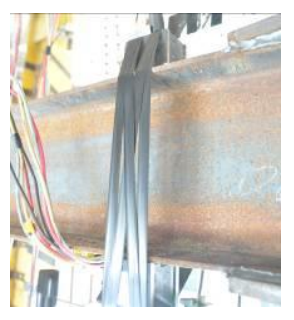

(a) Buckling of steel flange

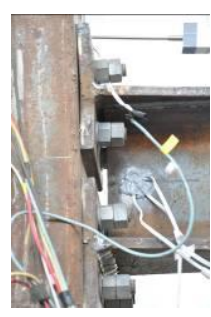

(b) Dislocation of $\mathrm{T}$ shape connector

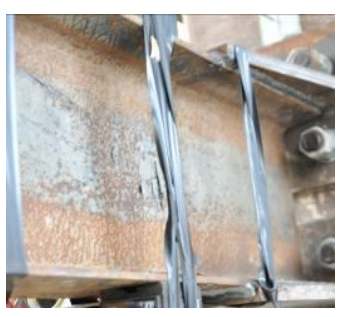

(c) Yielding line of the section 


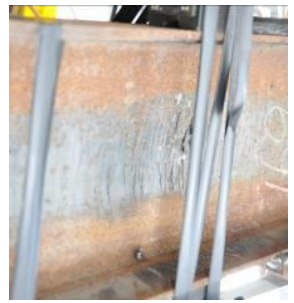

(d) Development of yielding region

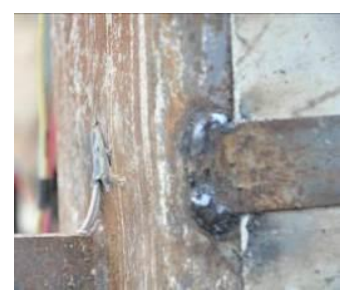

(e) Outbouncing of column bottom

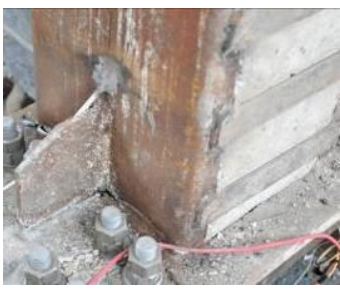

(f) Tensile fracture of the exterior column

Fig. 3 Local damage patterns

\section{Experimental results and discussion}

\subsection{Measured lateral load versus drift}

The lateral load- drift hysteresis curves are obtained, as shown in Fig 4. In the figure: $\delta_{\mathrm{PEC}}, \delta_{\text {whole }}, \delta_{1}$ and $\delta_{2}$ are the ratio of lateral displacement to height and

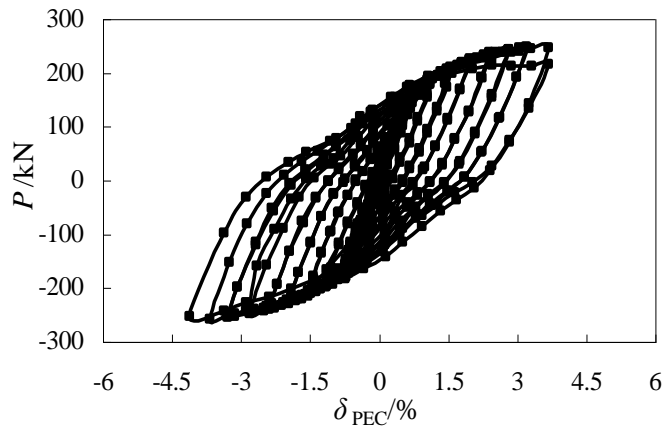

(a) PEC Column Top

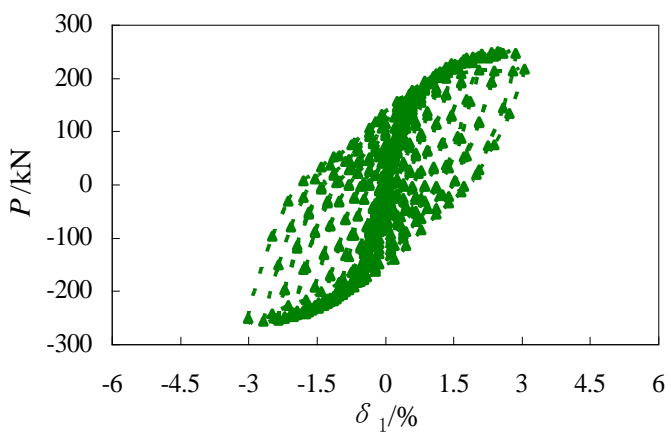

(c) First Floor areexpressed as $\delta_{\mathrm{PEC}}=\Delta_{\mathrm{PEC}} / \mathrm{h}_{\mathrm{PEC}}, \delta_{\text {overall }}=\Delta_{\text {overall }} / \mathrm{h}$ overall, $\delta_{1}=\Delta_{1} / \mathrm{h}_{1}, \delta_{2}=\Delta_{4} / \mathrm{h}_{2} . h_{\mathrm{PEC}}$, $h_{\text {overall }}, \mathrm{h}_{1}$ and $\mathrm{h}_{2}$ are the height of the top of the column, the overall height of the test piece, the height of the first floor and the height of the second floor, respectively. $\Delta_{\mathrm{PEC}}, \Delta_{\text {overall }}, \Delta_{1}$, and $\Delta_{2}$ are calculated from the displacement measurement of DT1, DT2, DT4, and DT5. To be specific, $\Delta_{\mathrm{PEC}}=\mathrm{DT} 1-\mathrm{DT} 5, \Delta$ overall $=\mathrm{DT} 2-\mathrm{DT} 5, \Delta_{1}=\mathrm{DT} 4-\mathrm{DT} 5, \Delta_{2}=\mathrm{DT} 2-\mathrm{DT} 4$

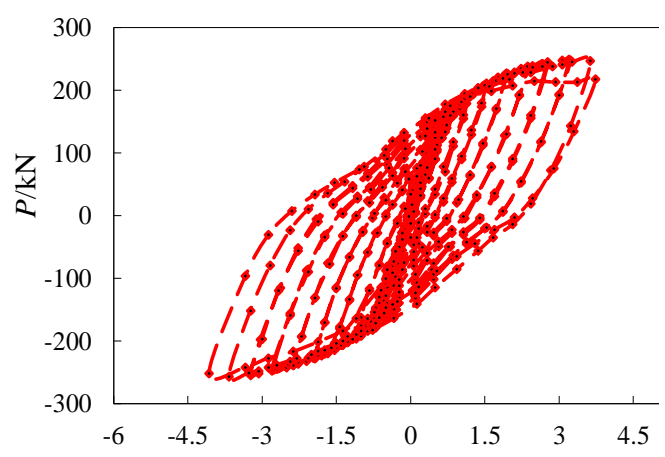

(b) Overall Specimen

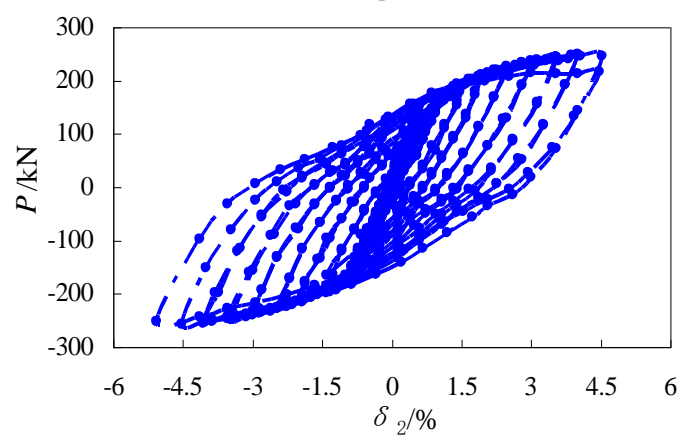

(d) Second Floor

Fig. 4 Hysteretic curves of lateral loading versus lateral drift

Table 3

Lateral resistance and frame responses at various stage of loading

\begin{tabular}{|c|c|c|c|c|c|}
\hline Stage & $\begin{array}{l}\text { Displacement } \\
\qquad / \mathrm{mm}\end{array}$ & $\begin{array}{l}\text { Shift } \\
\delta / \%\end{array}$ & $\begin{array}{l}\text { Lateral } \\
\text { resistance } \\
\text { push }(\mathrm{kN})\end{array}$ & $\begin{array}{l}\text { Lateral } \\
\text { resistance } \\
\text { pull }(\mathrm{kN})\end{array}$ & Observations \\
\hline 1 & 26 & 0.732 & 127.29 & 123.76 & Flange near the T-stub of the beam began to yield. \\
\hline 2 & 34 & 0.958 & 152.92 & 149.46 & The outer flange of the bottom of the PEC column successively entered yielding. \\
\hline 3 & 51 & 1.437 & 185.93 & 189.90 & $\begin{array}{l}\text { The yielding region of the beam extended to the web, and the T-stub of the beam was pulled } \\
\text { out. }\end{array}$ \\
\hline 4 & 68 & 1.915 & 210.93 & 211.75 & $\begin{array}{l}\text { The section near the T-stub of the beam was completely yielded to form a plastic hinge, and } \\
\text { the inner flange of the steel frame of the bottom of the PEC column also began to yield. }\end{array}$ \\
\hline 5 & 102 & 2.873 & 238.07 & 238.62 & $\begin{array}{l}\text { The plastic hinge region near the T-stub of all beam-ends was continuously developed to the } \\
\text { mid-span and yielding was further developed at the bottom of PEC column foot section. }\end{array}$ \\
\hline 6 & 136 & 3.831 & 249.27 & 256.84 & $\begin{array}{l}\text { Plastic hinges were formed at the beam ends and the bottom of PEC column near the T-stub, } \\
\text { and a plastic failure mechanism was formed. }\end{array}$ \\
\hline 7 & 153 & 4.310 & 246.51 & 251.99 & $\begin{array}{l}\text { The plastic hinge region near the T-stub of all beam-ends developed to the mid-span, } \\
\text { consequent concrete crushing observed at the bottom of PEC column and led to the obvious } \\
\text { bugleof the steel column flanges. }\end{array}$ \\
\hline
\end{tabular}


It can be seen from Fig. 4 that in the initial stage of loading, the T-stub and the PEC column were tightly connected by the pre-tightened bolts. Obviously, the load-displacement curve is linear in this stage. Along with the increasing of loading, the flange near the T-stub of the beam, the outer flange of the PEC column footing began to yield after reaching a displacement of $26 \mathrm{~mm}$ $(\delta=0.732 \%)$, and $34 \mathrm{~mm}(\delta=0.958 \%)$, respectively. The lateral resistance in the push and pull directions for those two stages is summarized in Table 3 . Debonding of the column was observed when reaching a displacement of $51 \mathrm{~mm}$ $(\delta=1.437 \%)$, thus the hysteresis curve exhibited a pinching phenomenon. The pinching phenomenon became more noticeable when displacement increased to $68 \mathrm{~mm}(\delta=1.915 \%)$, because the debonding of T-stub and column became more and more severe. Concrete crushing was observed because of the bulge of the flange when displacement reached $102 \mathrm{~mm}(\delta=2.873 \%)$. Lateral resistance of frame at various displacement levels is presented in Table 3, along with descriptions of frame performances based on the strain measurements and test observations.

Based on comparisons, it was found that the first floor was constrained due to the consolidation enhancement??? of the PEC column. The lateral deformation development rate was slower than that in the early stage of loading. As the loading progress continued, the lateral displacement deformation was accelerated. At the end of the loading, the lateral drift values of the top of the PEC column, the entire specimen, and the second layer all meet the requirements of inter-storey drift limit (i.e., within 1/30 of the frame structure at rare earthquake level). The lateral drift of the first floor also exceeds inter-storey drift limit (i.e., 1/50 of the frame structure at the design earthquake level). The tested structure exhibited excellent ductility under the seismic loading.

\subsection{Skeleton Curve}

The skeleton curves are shown in Fig 5. The skeleton curves of the top of PEC column and the entire specimen are coincident. The initial lateral stiffness of the first floor is the greatest, while the initial lateral stiffness of the second floor is the lowest. This is mainly because of the fixed constraint at the bottom of the PEC column. The constraint of the first floor of specimen is stronger than that of the second floor. The corresponding lateral displacements $\delta_{\mathrm{PEC}}, \delta_{\text {overall }}, \delta_{1}$ and $\delta_{2}$ of the specimen are $3.67 \%$ (4.12\%), 3.63\% (4.07\%), 2.87\% (3.00\%) and $4.53 \%(5.07 \%)$, respectively. The resistance of the specimen decreases insignificantly, which further indicated that the specimen presents good ductility.

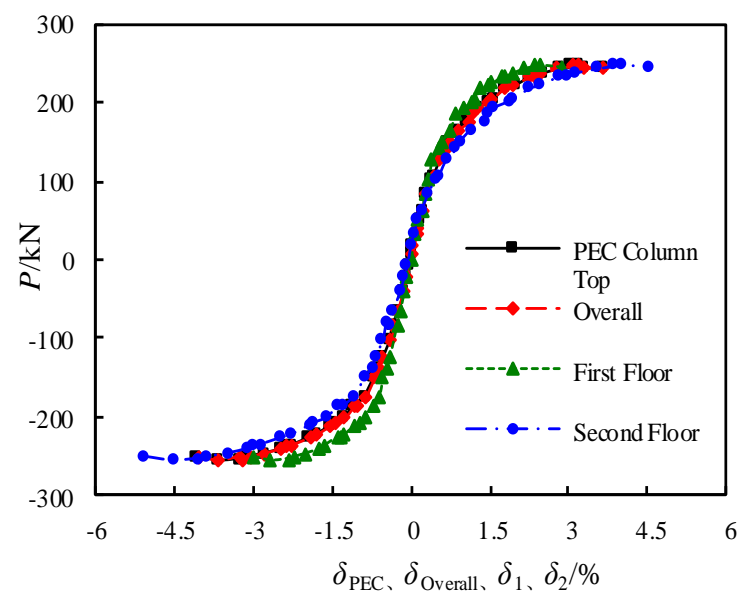

Fig. 5 Skeleton curves of the specimen

\subsection{Lateral Resistant Stiffness}

The reverse lateral stiffness of the specimen attenuates with the increasing number of cyclic loading, which reflecting the damage accumulated in the loading process. The lateral stiffness of the specimen is described by the peak secant stiffness $K_{\mathrm{p}}$ and the equivalent secant stiffness $K_{\mathrm{eq}}$. According to Eq. (1), the peak and the equivalent lateral stiffness of the specimens (i.e., at the same loading level) are depicted in Fig. 6.

$$
K_{\mathrm{p} i}=\frac{\left|P_{i}^{+}\right|+\left|P_{i}^{-}\right|}{\left|\Delta_{i}^{+}\right|+\left|\Delta_{i}^{-}\right|}
$$

$$
K_{e q i}^{+}=\frac{\left|P_{i}^{+}\right|}{\left|\Delta_{i}^{+}\right|+\left|\Delta_{i \mathrm{r}}^{+}\right|} \quad \text { or } \quad K_{e q i}^{-}=\frac{\left|P_{i}^{-}\right|}{\left|\Delta_{i}^{-}\right|+\left|\Delta_{i \mathrm{r}}^{-}\right|}
$$

where: $\Delta_{i}^{+} 、 \Delta_{i}^{-}$is the maximum lateral displacements in the push and pull directions of the loading cycle, respectively; $\Delta_{i r}{ }^{+}$and $\Delta_{i r}{ }^{-}$are the residual lateral displacements of the starting points in the push and pull directions of the loading cycle, respectively; $P_{i}^{+}$and $P_{i}$ are the lateral resistance corresponding to $\Delta_{i}^{+}$and $\Delta_{i}{ }^{-}$in the push and pull directions of the loading cycle.
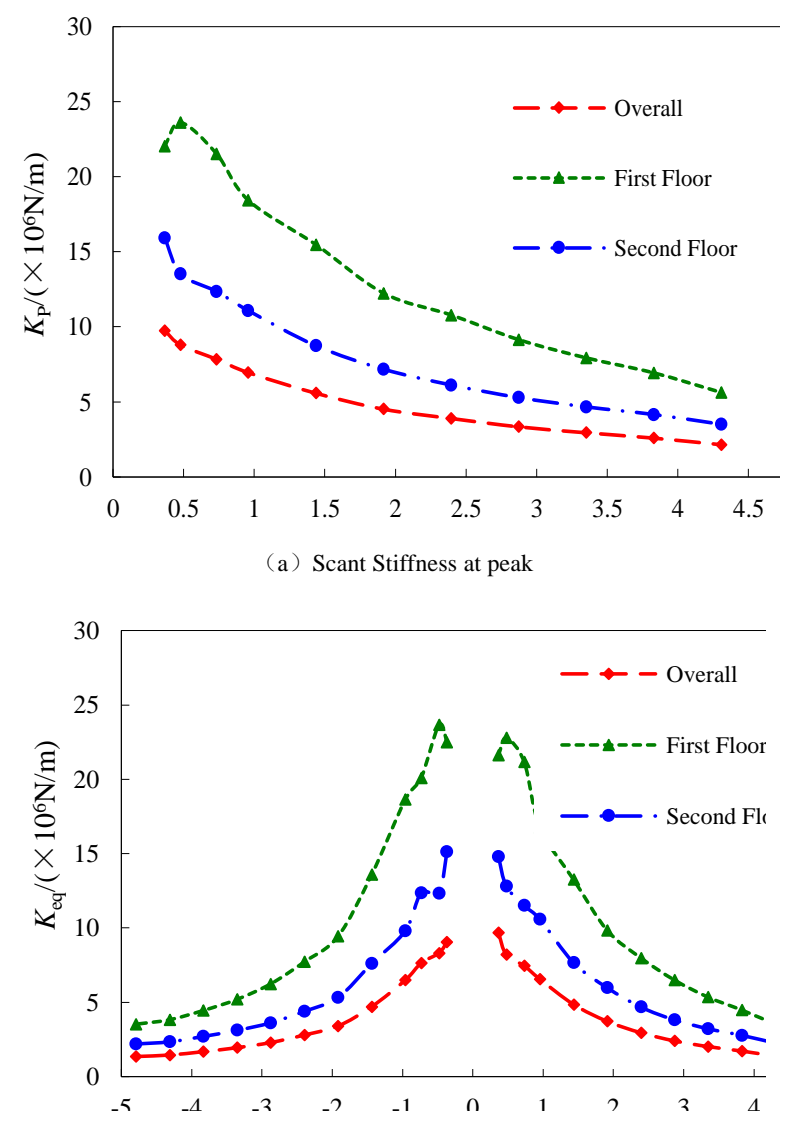

(b) Equivalent scant Stiffness

Fig. 6 Lateral stiffness degradation

It can be seen from Fig. 6 that, at the initial stage of loading, the anti-lateral stiffness of the first floor is greater due to the enhanced constrains at the bottom of PEC column,. The peak and equivalent secant stiffness of the overall frame, first floor, and second floor are summarized in Table 4 at various loading stages It was observed that when loaded to a displacement of $26 \mathrm{~mm}(\delta=0.732 \%)$, the cross-section flange near the T-stub of the beam began to yield, the lateral stiffness of the specimen showed a significant attenuation trend; When the displacement increased to $68 \mathrm{~mm}(\delta=1.915 \%)$, the section near the T-stub of the beam was completely yielded and formed a plastic hinge, and the inner flange of the steel frame of the PEC column was also yielded at this time. The attenuation rates of the lateral stiffness of the specimen became smaller. The corresponding attenuations for peak secant stiffness were 54\%, 45\%, and 55\%, respectively, for the overall frame, first and second floor. The corresponding values of the equivalent secant stiffness were $62 \%, 55 \%$ and $60 \%$ for pushing direction, and $62 \%, 58 \%$ and $65 \%$ for pulling direction, respectively. When loaded to a displacement of $102 \mathrm{~mm}(\delta=2.873 \%)$, the plastic hinge area of the section near the T-stub of all beam ends continuously extended to the PEC column, the steel frame yielding cross-section center and the concrete began to crush, and the lateral stiffness attenuation tendency of the specimen became gentle. Subsequently, when the lateral displacement reached $153 \mathrm{~mm}(\delta=4.310 \%)$, The corresponding attenuations were $78 \%, 75 \%$, and $78 \%$, respectively for peak secant stiffness. The equivalent scant stiffness were $86 \%, 84 \%$, and $85 \%$ for pushing direction and $84 \%, 85 \%$ and $82 \%$ for pulling direction, respectively. 
Table 4

Peak and equivalent secant stiffness

\begin{tabular}{|c|c|c|c|c|c|c|c|c|c|}
\hline \multirow{3}{*}{ Stages } & \multicolumn{3}{|c|}{ Peak secant stiffness $(\mathrm{N} / \mathrm{m})$} & \multicolumn{6}{|c|}{ Equivalent Scant Stiffness (N/m) } \\
\hline & \multirow[b]{2}{*}{$\begin{array}{l}\text { Overall } \\
\text { frame }\end{array}$} & \multirow[b]{2}{*}{$\begin{array}{l}\text { First } \\
\text { floor }\end{array}$} & \multirow[b]{2}{*}{ Second floor } & \multicolumn{3}{|c|}{ Push Direction } & \multicolumn{3}{|c|}{ Pull Direction } \\
\hline & & & & $\begin{array}{l}\text { Overall } \\
\text { frame }\end{array}$ & $\begin{array}{l}\text { First } \\
\text { floor }\end{array}$ & Second floor & Overall frame & $\begin{array}{l}\text { First } \\
\text { floor }\end{array}$ & Second floor \\
\hline Initial & $9.75 \times 10^{6}$ & $22.05 \times 10^{6}$ & $15.93 \times 10^{6}$ & $9.68 \times 10^{6}$ & $21.61 \times 10^{6}$ & $14.80 \times 10^{6}$ & $9.05 \times 10^{6}$ & $22.49 \times 10^{6}$ & $15.12 \times 10^{6}$ \\
\hline $\begin{array}{c}68 \mathrm{~mm} \\
(\delta=1.915 \%)\end{array}$ & $4.52 \times 10^{6}$ & $12.23 \times 10^{6}$ & $7.17 \times 10^{6}$ & $3.72 \times 10^{6}$ & $9.83 \times 10^{6}$ & $5.98 \times 10^{6}$ & $3.40 \times 10^{6}$ & $9.43 \times 10^{6}$ & $5.32 \times 10^{6}$ \\
\hline $\begin{array}{c}153 \mathrm{~mm} \\
(\delta=4.310 \%)\end{array}$ & $2.15 \times 10^{6}$ & $5.61 \times 10^{6}$ & $3.49 \times 10^{6}$ & $1.27 \times 10^{6}$ & $3.52 \times 10^{6}$ & $2.25 \times 10^{6}$ & $1.35 \times 10^{6}$ & $3.52 \times 10^{6}$ & $2.20 \times 10^{6}$ \\
\hline
\end{tabular}

\subsection{Mechanical Performance of connection Joints}

In the conventional structural system, the joint is the key part to ensure structural integrity and the force transfer mechanism. In this section, the mechanical properties of connection joints and joint regions are analyzed.

\subsubsection{Configuration of joints}

The rotation angle of the connection joints was measured by the displacement gauge. $\theta_{1}$ is the relative rotation at the upper and lower joints between the end of the west beam and the PEC column. $\theta_{2}$ is the relative rotation
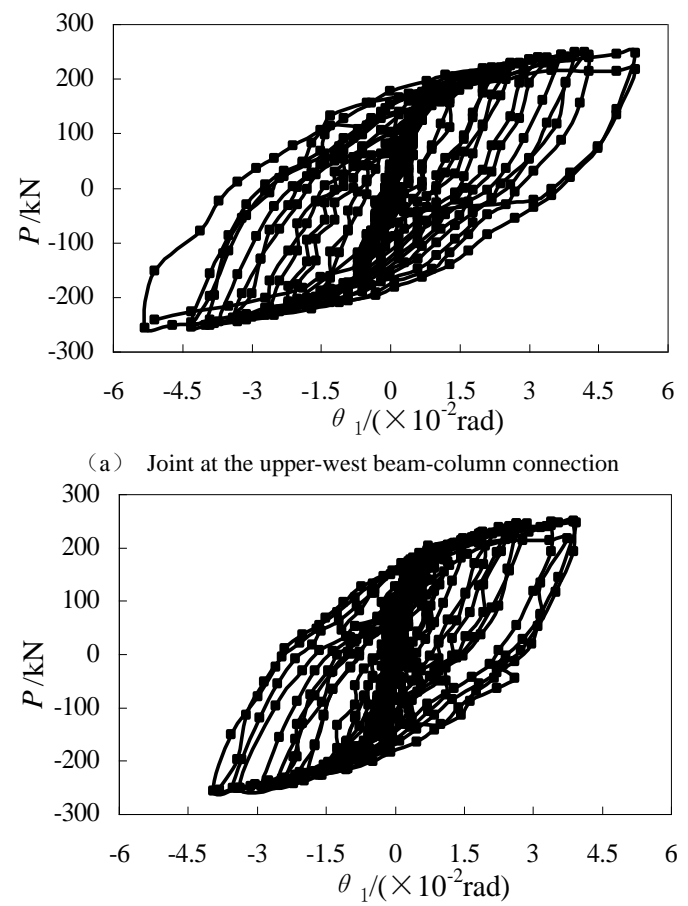

(c) Joint at the lower-west beam-column connection at the upper and lower joints between the edge of beams and T-stub flange plate, which can be calculated according to Eq (2),

$\theta_{1 / 2}=\frac{4_{\text {upper }}-\Delta_{\text {lower }}}{l}$

where: $\Delta_{\text {upper }}, \Delta_{\text {lower }}$ is the upper and lower displacements of the joint; $l$ is the distance between the upper and lower displacement measurement points. The calculated rotation angle results are shown in Fig. 7.
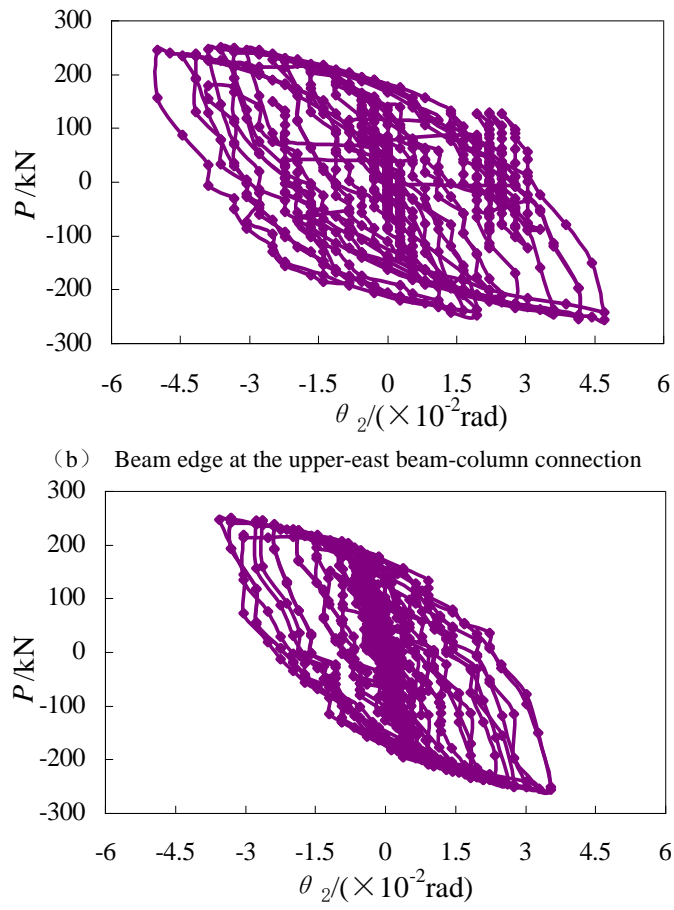

(d) Beam edge at the lower-east beam-column connection

Fig.7 P- $\theta$ hysteresis loops of connection or beam-end
It can be seen from Fig. 7 that the specimen was elastic state in the initial stage of loading, , and the rotation angle between the joint and the beam end were quite small. When the specimen was loaded to a displacement of $34 \mathrm{~mm}(\delta$ $=0.958 \%$ ), the rotation angle between the joint and the beam end increased significantly, because the cross-section flange near the beam end T-stub started to yield as well as the outer flange of the steel frame at the bottom of the PEC column. When the displacement reached $68 \mathrm{~mm}(\delta=1.915 \%)$, the cross-section of the T-stub part near the beam was substantially yielded and formed a plastic hinge. The inner flange at the bottom of the PEC column also began the yielding state, and the bond between the T-stub and the PEC column at the tension side of the beam was obviously damaged. The rotation angle and the beam end angle thus increased obviously. When the specimen was loaded to a displacement of $102 \mathrm{~mm}(\delta=2.873 \%)$, the plastic hinge area near the T-stub of all beam ends was continuously developed in the middle of the span. The yielding zone of the steel frame at the bottom of the PEC column further developed towards the middle of the section, and the concrete began to crush. The stiffness distribution along the height of the specimen tended to be uniform, and the increasing trend of rotation angle between the joint and the beam end angle was delayed.

When the specimen was loaded to a displacement of $136 \mathrm{~mm}(\delta=3.831 \%)$, the plastic mechanism was formed as aforementioned. The structure was transformed into a plastic failure mechanism, and the rotation angle at the connection joint and the beam end increased dramatically. When the specimen was loaded to $153 \mathrm{~mm}$ level $(\delta=4.310 \%)$, the plastic hinge area near the T-stub of all beam ends developed seriously in the middle of the span, and the concrete crushed at the bottom of the PEC column. The resistance of the specimen was reduced. At this time, the rotation angles of the upper and lower joint of the west PEC column were respectively $0.053 \mathrm{rad}$ and $0.395 \mathrm{rad}$. The equivalent rotation values for the east side were $0.052 \mathrm{rad}$ and $0.0356 \mathrm{rad}$, respectively. All rotations exceeded the inter-storey drift limit, that is, 1/30 of the frame structure at the considered maximum earthquake level. In addition, the bottom of PEC column was just connected with the ground beams, and the steel skeleton at the bottom entered the yielding after the yielding of the beam ends. Therefore, the yielding process of the beam section near the end of the second-floor T-stub developed faster. The loading and unloading effects were obvious in the later stages, which led to the achievement of the full rotational capacity of the second-floor beam end joint.

\subsubsection{Performance of the joint region}

The shear strain $\gamma$ of the joint region is calculated based on Eq. (3). The calculation results are depicted in Fig. 8.

$\gamma=2 \times \varepsilon_{45^{\circ}}-\varepsilon_{90^{\circ}}-\varepsilon_{0}$

Where: $\varepsilon_{45^{\circ}}{ }^{\circ}, \varepsilon_{90^{\circ}}$, and $\varepsilon_{0}$ correspond to the measured strain of the $45^{\circ}, 90^{\circ}$, and $0^{\circ}$ in the joint region. 


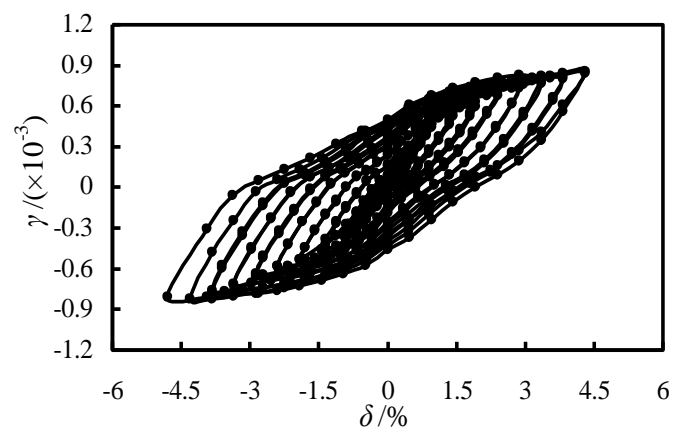

(a) upper-west beam-column region

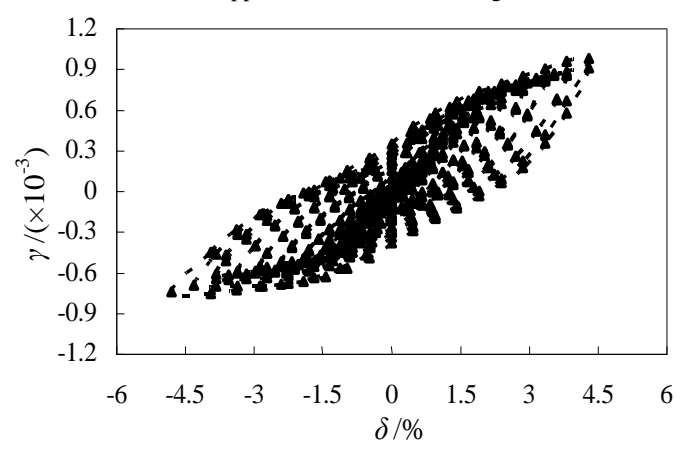

(c) lower-west beam-column region

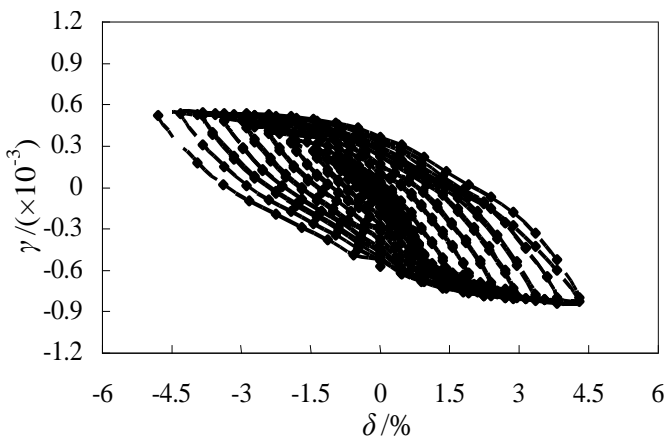

(b) upper-east beam-column region

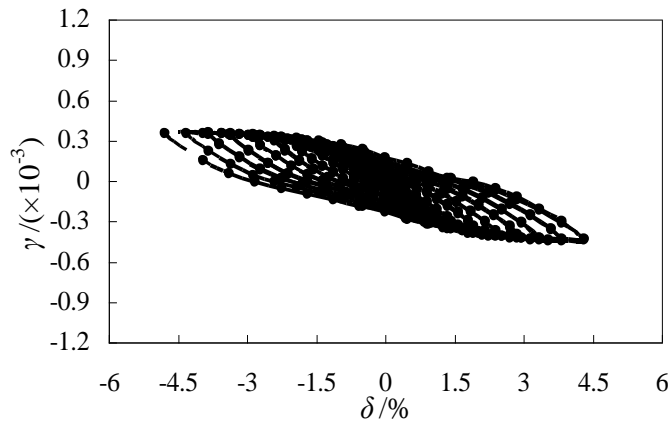

(d) lower-east beam-column region

Fig. 8 Hysteretic loops of shear deformation in the panel zone

It can be seen from Fig. 8 that in the initial stage of loading, the shear deformation hysteretic curve in the panel zone was quite small. After the specimen was loaded to a displacement of $34 \mathrm{~mm}(\delta=0.958 \%)$, the cross-section flange at the beam end near the T-stub, and the outer flange of the steel frame at the bottom of the PEC column began to yield. The shear deformation in the joint region significantly increased. When the specimen was loaded to a displacement of $153 \mathrm{~mm}(\delta=4.310 \%)$, all beam ends near the T-stub formed plastic hinge at the nearby section developed to the middle span. The concrete crushed at the bottom of the PEC column and resulted in an obvious bulge of the steel skeleton flange. The resistance of the specimen was reduced. The maximum shear deformation of all joint regions $\gamma_{\max }$ was $979 \mu \varepsilon$, which indicates that strengthening plate at the joint significantly improved the confinement effect of the concrete in the joint region of the specimen. The force transfer mechanism of the concrete diagonal zone in the joint zone was achieved through the bolt connection. The shear resistance of the joint region met the seismic resistance requirements of achieving the "strong joint".

\subsection{Ductility and energy dissipation capacity}

\subsubsection{Ductility}

The ductility of the structure is generally evaluated by the dimensionless coefficient of displacement ductility $\mu$, which can be calculated using Eq. (4).

$\mu=\frac{\delta_{u}}{\delta_{y}}$

Where $\delta_{\mathrm{y}}$ is the corresponding lateral displacement when the specimen begins to yield, which is determined based on the test observation and the measured strain results; $\delta_{\mathrm{u}}$ is the lateral drift limit corresponded to $85 \%$ of the peak load of the specimen.

Table 5 summarizes the coefficients of displacement ductility of the overall specimen and each floor. It can be seen from Table 5 that the overall coefficients of displacement ductility is between the those of the first and the second floor. In addition, the first-floor coefficient of displacement ductility is greater than that of the second floor. This may due to the bottom of the PEC column were fully restrained. Therefore, the constraint of column at first floor is greater than that of the second floor. At the termination of the loading test, the resistance of the specimen has not reduced to below $85 \%$ of the ultimate bearing capacity, and the coefficient of displacement ductility of the overall test frame and each floor are still greater than 3 . This indicates that the tested structure presents good ductility when subjected to seismic loading.
Table 5

Ductility coefficients of the specimen

\begin{tabular}{ccccc}
\hline \multirow{2}{*}{ Component } & Loading & $\delta_{\mathrm{y}} / \%$ & $\delta_{\mathrm{u}} / \%$ & $\mu$ \\
\hline \multirow{2}{*}{ Overall } & Direction & 1.133 & 3.633 & $>3.21$ \\
& Positive & 1.100 & 4.067 & $>3.70$ \\
& Negative & 0.867 & 2.867 & $>3.308$ \\
\multirow{2}{*}{ First Floor } & Positive & 0.733 & 3.000 & $>4.091$ \\
& Negative & 1.467 & 4.533 & $>3.091$ \\
& Positive & 1.400 & 5.067 & $>3.619$ \\
\hline
\end{tabular}

\subsubsection{Energy dissipation}

In general, the energy dissipation capacity of a structure is used to characterize the plastic damage when subjected to cyclic loading. Under the low-cycle cyclic loading, the degree of damage of structure can be represented by the area of the hysteresis loop. A larger the hysteresis loop area indicates the structure exhibits more excellent energy-dissipation capacity and better seismic resistance. In this study, the energy dissipation of the specimen is analyzed by hysteretic energy dissipation (i.e., hysteresis loop area) and equivalent viscous damping ratio.

\section{(1) Hysteresis energy-dissipation}

The evolution curve of the hysteretic energy $A_{\mathrm{E}}$ is the mean area of the hysteresis loop at various loading stages of the specimen. Based on the measured lateral load- drift relationship in Fig. 4, the evolution curve of the hysteretic energy $A_{\mathrm{E}}$ is calculated, as shown in Fig. 9.

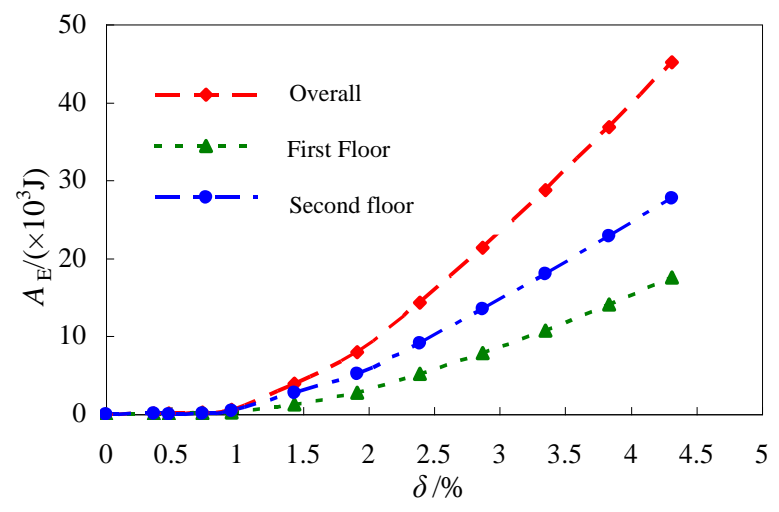

Fig. 9 Hysteretic energy dissipation curves 
It can be concluded from Fig. 9 that before the specimen was loaded to the displacement of $34 \mathrm{~mm}(\delta=0.958 \%)$, no significant energy consumption was observed. Then, the specimen started to dissipate energy through the yielding of the cross-section at the T-stub near the beam end and through the yielding at the bottom of PEC column. The yielding of the steel frame also obviously increased the energy dissipation. When the specimen was loaded to the displacement of 68 $\mathrm{mm}(\delta=1.915 \%)$, the full cross-section of the T-stub near the beam was yielded to form a plastic hinge, and the inner flange of the steel frame at the bottom of PEC column was also in the yielding state, more energy was dissipated. Because the PEC column was fully fixed at the bottom, the restraint of first-floor footing was higher than that of the second floor. Therefore, the evolution process of plastic damage to the first floor lag behind the second floor. The energy consumption of the second floor of the specimen was obviously greater than that of the first floor.

(2)Equivalent viscous damping ratio

The equivalent viscous damping ratio $\zeta_{\mathrm{eq}}$ is calculated according to Eq. (5)

$\zeta_{\mathrm{eq}}=\frac{1}{2 \pi} \cdot \frac{A_{E i}}{\left(4_{i}^{+} \times P_{i}^{+}+4_{i}^{-} \times P_{i}^{-}\right) / 2}$

Where: $A_{E i}$ is the area covered by the hysteresis loop, $\Delta_{i}^{+}$and $\Delta_{i}^{-}$are the maximum lateral displacements in the push and pull directions of the hysteresis loop. $P_{i}^{+}$and $P_{i}^{-}$are the lateral resistance of the specimen corresponding to $\Delta_{i}^{+}$and $\Delta_{i}{ }^{-}$, respectively.

Based on the measured lateral load- drift relationship in Fig. 4, the curves of the equivalent viscous damping coefficient during the loading process can be calculated. It can be seen from Fig. 10 that at the initial stage of the test loading, the test specimen was in the elastic state, and a small amount of energy was dissipated through the joint compaction, frictional slip at the joint, and the concrete compression of the PEC column, but the equivalent viscous damping ratios of the overall frame and each floor were all less than 0.05 , which is consistent with the recommended values by the Code for Seismic Design of Buildings [7]. When the specimen was loaded to a displacement of $34 \mathrm{~mm}$ $(\delta=0.958 \%)$, the cross-section flange near the T-stub of the beam began to yield, and the outer flange of the steel frame at the bottom of the PEC column began to yield, and the equivalent viscous damping ratios of the whole frame and the floors increased significantly. When the specimen was loaded to a displacement of $68 \mathrm{~mm}(\delta=1.915 \%)$, the cross-section of the T-stub near the beam end yielded and formed a plastic hinge. The inner flange of the steel frame at the PEC column also was in the yielding state. The effect of the viscous damping ratio tended to be minor. Before the specimen was loaded to the displacement of 68 $\mathrm{mm}(\delta=1.915 \%)$, the equivalent viscous damping ratio of the layer was slightly smaller than the second floor. The yielding development in the structure and concrete crushing were dramatic. The equivalent viscous damping ratio of the first floor was slightly faster than that of the second floor. At the termination of the loading, the equivalent viscous damping ratio of the overall frame, first and second floors of the specimen were $0.261,0.264$, and 0.259 , respectively. The evolution process of the equivalent viscous damping ratio of the overall frame and the floors exhibited similar trends.

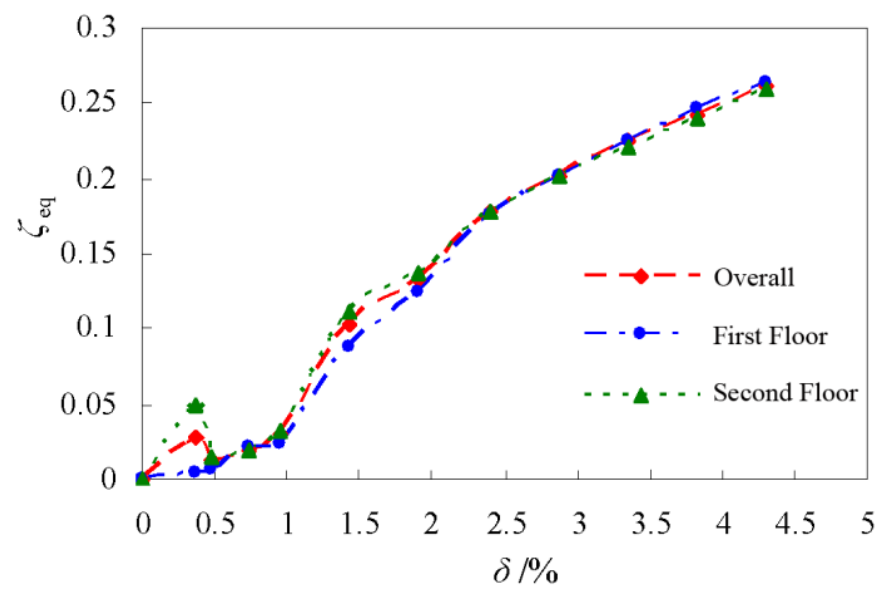

Fig. 10 Equivalent viscous damping ratios

\section{Plastic collapse mechanism}

Based on the experimental observations and the analysis of the measured data, the evolution process of the plastic structure of the specimen under low cyclic loading is described as follows. The specimen was loaded to a displacement of $68 \mathrm{~mm}(\delta=1.915 \%)$, and the cross-section of the T-stub near the beam substantially yielded for all section and formed a plastic hinge. When the specimen was loaded to a displacement of $136 \mathrm{~mm}(\delta=3.831 \%)$, the steel skeleton at the bottom of the PEC column was fully yielded, and the concrete was crushed and peeled off to form a plastic hinge. Corresponding details can be found in Fig. 3. The ideal ductile energy dissipation model of the frame structure. The structure of the specimen was transformed into a plastic failure mechanism, as shown in Fig 11.

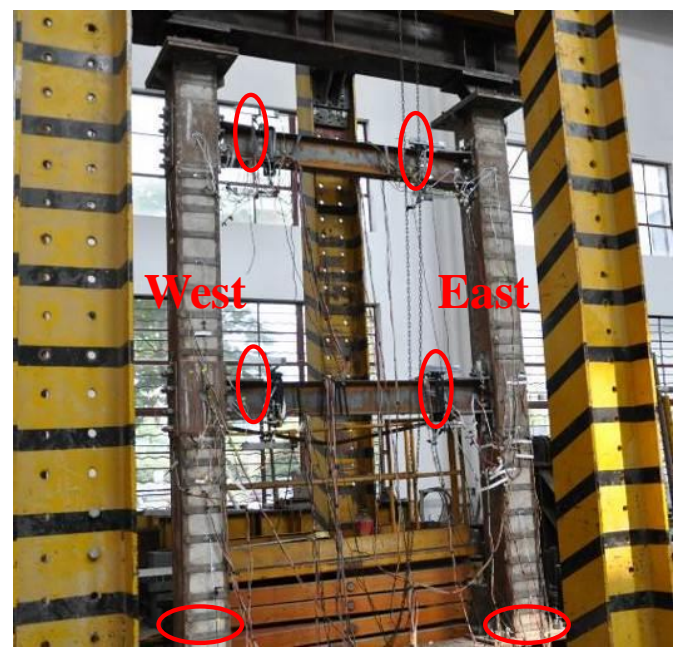

Fig. 11 The ductile failure mode of the specimen

\section{Conclusions}

1) T-stub welding reinforced connection enhanced the integrity, lateral resistance, and initial lateral stiffness of the specimen. The specimen's ultimate lateral resistance was $249.27 \mathrm{kN}$ (push) and $256.84 \mathrm{kN}$ (pull), respectively. The initial peak secant stiffness was $9.68 \times 10^{6} \mathrm{~N} / \mathrm{m}$.

2) The beam-column joint region of the specimen provides good confinement of the concrete by installing the joint reinforcement plate. Force transfer mechanism through the forming of concrete diagonal pressure zone was achieved due to the bolt connection. It enhanced the shear resistance of the joint and better met the requirements of seismic resistance by forming the "strong joints".

3) The shape of the hysteresis curve of the specimen was full. At the end of the test, the lateral resistance did not drop below $85 \%$ of the ultimate bearing capacity. The overall lateral drifting, ductility coefficient, and equivalent viscous damping ratio reached 3.63\% (push) / 4.07\% (pull), 3.21 (push)/3.70 (pull), and 0.261 , respectively, which indicated that the specimen exhibited superior deformation and seismic resistance, excellent ductility, and energy dissipation capacity.

4) T-stub welding reinforced connection PEC column-steel beam composite frame specimen developed plastic failure mechanism because the T-stub end beam section and PEC column footing successively form plastic hinges, which realizes the ideal ductility energy dissipation mode of the frame structure.

Along with previous investigations on PEC column components, joints, and interlayer substructures, the seismic performance of large-scale PEC column structures were verified in this study. The test results revealed that the proposed frame structure had good potential to be implemented in the seismic sign for enhancing strong lateral stiffness, better ductility, and energy dissipation capacity. However, more experiments on this new type of structure might be necessary, especially the seismic performance under the biaxial lateral loading.

\section{Acknowledgment}

This study was finally supported by the National Natural Science Foundation of China (No. 51478286 and 51078247). The views and findings reported here, however, are those of the writers alone, and not necessarily the views of the sponsoring agency.

\section{Reference}

[1] MUISE J. Behaviour of Simple Framing Connections to Partially Concrete Encased H Section Columns.Master's Thesis, the University of Toronto, Torroto, Canada, 2000. 
[2] CHICOINE T, MASSICOTTE B, TREMBLAY R. Long-Term Behavior and Strength of Partially Encased Composite Columns with Built-up Shapes. ASCE Journal of Structural Engineering, 2003, 129(2):141-150.

[3] PRICKETT B S, DRIVER RG. Behaviour of Partially Concrete Encased Columns Made with High-Performance Concrete. Structural Engineering Report 262, Dept. of Civil and Environment Engineering, University of Alberta, Edmonton Canada, 2006.

[4] YIN Yingzi, ZHAO Gentian, SHEN Xiangdong. Test study of PEC column with welding H shapes under concentric axial loading. Journal of Industry Buildings, 2008, 38(7): 89-91(in Chinese)) 2008, 29(2): 51-62. (in Chinese)

[5] FANG Youzhen, GU Qiang, SHEN Lin, et al. Hysteretic behavior study of PEC columns (weak axis) fabricated with thin-walled built-up section by full scale. Journal of Building Structures, 2012, 33(4):113-120. (in Chinese)

[6] FANG Youzhen, LU Chengduo, MA Ji, et al. Experimental study on hysteretic behaviors of PEC columns(weak axis) fabricated with crimping thin-walled built-up section by full scale. Journal of Civil Engineering, 2013, 46(1):24-33. (in Chinese)

[7] GB50011-2010. Code for seismic design of buildings, China Architecture \& Building Press, Beijing, China, 2010.

[8] Chen Z, Qin Y, Wang X. Development of connections to concrete-filled rectangular tubular columns. Adv Steel Constr. 2015;11(4):408-26.

[9] HE Yibin, LI Yi, CAO Haixin, et al. Experimental research on and calculation method for the shear strength of composite column-to-beam connections through T-stubs. Journal of Hunan University (Natural Sciences), 2012, 39(11): 1-6. (in Chinese)

[10] RICES J M, PENG S W, LU L W. Seismic behavior of composite concrete filled steel tube column-wide flange beam moment connections. ASCE Journal of Structural Engineering, 2004, 130(2):223-232.

[11] CAO Xianlei, HAO Jiping, SHEN Chenjun. Analysis of the anti-seismic capacity of T-stub beam-column joint of the steel frame under cyclic load. Steel Construction, 2008, 23(7):30-33、38. (in Chinese)

[12] WANG Xiantie. Behavior research and aseismic design criterion on new type connections of concrete-filled square tubular column and steel beam. Master's Thesis, Xi'an University of
Architecture and Technology, Xi'an, China, 2007. (in Chinese)

[13] FANG Youzhen, GU Qiang, YAO Jiangfeng, et al. Experimental study on Seismic Performance of new PEC column fabricated with crimping thin-walled built-up section—steel beam interior connections. Journal of Building Structures, 2014, 47(7):53-62. (in Chinese)

[14] FANG Youzhen, GU Qiang, LU Senqiang, et al. Experimental investigation on node Seismic Performance of a new PEC column - steel beam with T-shape welding strengthened connection. Journal of Experimental Mechanics, 2016, 31(1):103-112. (in Chinese)

[15] FANG Youzhen, WANG Yuxi, NIU Rongbin, et al. Experimental study on collapse mechanism of interstory substructure of PEC column-steel beam composite frame with welded T-stud strengthened connection. Journal of Xi'an Univ. of Arch. \& Tech.(Natural Science Edition), 2016, 48(4):468-476. (in Chinese)

[16] WANG Yuxi, FANG Youzhen, SHEN Xiaoming et al. Numerical simulation of interstory seismic performance of composite frame with new type PEC column-steel beam T-type jointer. World Earthquake Engineering, 2017, 31(1):100-109. (in Chinese)

[17] Bezerra LM, Bonilla J, Silva WA, Matias WT. Experimental and numerical studies of bolted T-stub steel connection with different flange thicknesses connected to a rigid base. Eng Struct. 2020; 218 (December 2019): 110770.

[18] Sebbagh HR, Kerdal DED, Abidelah A, Bouchaïr A. T-stubs with two and four bolts under monotonic and cyclic loading. J Constr Steel Res. 2021;178.

[19] Ma HW, Zheng H, Zhang W, Tang ZZ. Experimental and numerical study of mechanical properties for the double-ribbed reinforced beam-column connection. Adv Steel Constr. 2020;16(4):297-309.

[20] Tjahjanto H, Macrae G, Abu A. Behaviour of improved direct-welded connections in square cfst column moment frames under bidirectional loading. Adv Steel Constr. 2020;16(2):156-69.

[21] MATHEW D S. Seismic testing and analytical studies for development of new seismic force resisting systems for metal buildings.Master's Thesis, : University of California-San Diego, San Diego, USA, 2013 